That $A k k a d \bar{a}$ and $\bar{S} u[$ merā $]$ may refer to the languages is not only possible, but probable. That the position of the writing on the tablet is referred to, however, one may be allowed to doubt. Supposing that the upper line were Akkadian and the lower line Sumerian, a man who could read would know this without being told, and to one who could not read such information would be useless.

Perhaps K. 14,013 is a parallel text to K. 11,856 , where, after references to EYYYY EYYY - 다 $2+-\xi y, \hat{e}-d u b-b a-g u-l a$, "the house of the great tablet," or better, "the great tablet-

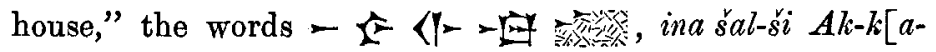
$d a-a$ ?] occur. This would seem to refer to the rooms, or shelves, or receptacles, where the various classes of tablets were kept, for it means "in the third the Akkadian"; and that the language is referred to here, is proved by the nonSemitic line, which has $\rightarrow$ t eme Uri, "tongue of Akkad."

But this, like the others, is tantalizingly incomplete.

I am glad to have Professor Tiele's criticism, as it proves that my language, notwithstanding my desire to be cautious, was not sufficiently guarded and precise.

Theophilus G. Pinches.

7. Note on Indian CoIns and Inscriptions.

Naini Tal, N.W.P.

May 28, 1900.

Dear Professor Rhys Davids,-At pp. 115 and 116 of the Journal for January, 1900, Mr. Rapson discusses the coins of Virasena and refers to the question whether they should be classed with the so-called Muttra coins. There cannot be the slightest doubt that they are found most commonly in the places where the Muttra coins are found, but they are also found further to the west and south. Most of my Muttra coins ( $I$ have ten of those figured in plate viii, Cunningham's " Coins of Ancient India," besides a number 
I am still working at) were found on the ancient site of Sankisa or the neighbouring village of Sarai Aghat, the former in the Farukhabad district and the latter in Etab. I have never, however, got a Muttra coin in Qanauj, though I have obtained several of Virasena there. A more important fact, howerer, is the inscription I found in the south of the Farukhabad district at Jānkhat, a village five miles southwest by south of Thatia, and nine miles south-east of Tirwa, in the Tirwa tahsil (the place is marked on the map in the Gazetteer of the Farukhabad district). As is usual in those parts, every carved stone found is placed on a mound in or near the village site, and the collection is called the Gawän devi, or village gods. When in camp I always examined these, and on January 21st, 1896, as I was leaving the village $I$ found an inscription on the back of one stone, the front of which had a carving, the nature of which I forget. I had no materials for taking an estampage and at that time did not know the Brahmi letters, but took two eye-copies. From a volume of Cunningham's Archaeological Reports I made out the name Virasena written exactly as it is on the coins, and a few months later Mr. V. A. Smith, as soon as he saw the copy, read the date 113 Grishma. Looking at the copy again, I am inclined to think that between the word Virasena and the date the word Samvatsara occurs, and the symbol read by Mr. Smith as 100 is really the final -ra of Samvatsara. This would make the date 13 of the Samvat era, or в.c. 45 . I attempted to get the stone sent to the Lucknow Museum, but the owner of the village, a man much under the influence of the Brahmans, wrote that the villagers refused to let it go, and I had left the district before I realized the importance of the find. Dr. Führer promised to send a man to take a cast or estampage, but apparently omitted to do so. If possible I shall go there next cold weather, but it is uncertain whether I can get there, as the place is some distance from the railway. The middle of the lower part of the stone has lost the inscription, and the appearance led me to believe it had been used to sharpen chisels on. 
On p. 110 of the same number Mr. Rapson publishes a Muttra coin with a now name, Śșadātasa, and writes that only three specimens are known. Three years ago I sent a specimen, which I still possess, to the Bengal Asiatic Society for publication. The Society could not allow a plate for my paper, which was therefore not published, and at that time I thought the symbol for $\dot{S}_{e}$ - was a combination of $t a$ - and $r a$. There is no doubt, however, to my mind, that Mr. Rapson's reading of Seșa is correct. The letter immediately before $\hat{S} e$ on my coin is blurred, but appears to be the combination -jño as in No. 10 of Mr. Rapson's paper. The top of the -da-is gone, so that it is impossible to say whether it has the long $-\bar{a}-$ attached to it or not.

I should also like to mention that my specimen of Brahma Mitra (Cunn., Coins of Anc. Ind., pl. viii, No. 12) is either of mixed metal or was washed with silver, and I have one round coin of Virasena.-Yours sincerely,

RichaRd BuRn.

\section{Sanskrit Deed of Sale.}

\section{Göttingen.}

June 17, 1900.

Dear Sir,-In his interesting article on "A Sanskrit Deed of Sale concerning a Kaśmīrian Mahābbārata Manuscript," Dr. Stein, above p. 191, has stated that the date of that deed corresponds to Thursday, the 10th July, 1682; but the 10th July, 1682, old style, was a Monday, and new style, a Friday. Really the original date, "Thursday, the 1st ${ }^{1}$ of the dạk half of Âsvina of the laukika year 58 [i.e. the Saptarsi year 4758]," corresponds to Thursday, the 7th September, 1682, old style.-Yours truly,

F. KIELHORN.

1 On p. 191 , line 3, Dr. Stein has "the 8th day," but from pp. 188 and 189 it is clear that the dsy was the lst. 